\title{
High Endothelial Venule-Like Vessels and Lymphocyte Recruitment in Diffuse Sclerosing Variant of Papillary Thyroid Carcinoma
}

Shulin Low ${ }^{1}$, Yasuhiro Sakai ${ }^{1}$, Hitomi Hoshino ${ }^{1}$, Mitsuyoshi Hirokawa ${ }^{2}$, Hiroto Kawashima ${ }^{3}$, Kayoko Higuchi ${ }^{4}$, Yoshiaki Imamura ${ }^{5}$ and Motohiro Kobayashi ${ }^{1}$

${ }^{1}$ Department of Tumor Pathology, Faculty of Medical Sciences, University of Fukui, Eiheiji,

${ }^{2}$ Department of Diagnostic Pathology, Kuma Hospital, Kobe, ${ }^{3}$ Department of Microbiology and Molecular Genetics, Graduate School of Pharmaceutical Sciences, Chiba University, Chiba,

${ }^{4}$ Department of Diagnostic Pathology, Aizawa Hospital, Matsumoto, and ${ }^{5}$ Division of Surgical Pathology, University of Fukui Hospital, Eiheiji, Japan

Running head: HEV-LIKE VESSELS IN PAPILLARY THYROID CARCINOMA

Address for correspondence: Motohiro Kobayashi, Department of Tumor Pathology, Faculty of Medical Sciences, University of Fukui, 23-3 Matsuoka-Shimoaizuki, Eiheiji, Fukui 910-1193, Japan. E-mail: motokoba@u-fukui.ac.jp

TEL: +81-776-61-8319 / FAX: +81-776-61-8103 


\section{Summary}

Diffuse sclerosing variant of papillary thyroid carcinoma (DSPTC) is a rare subtype of papillary thyroid carcinoma with a high incidence of lymph node metastasis. One of its characteristic histological features is the presence of dense lymphocyte infiltrates; however, how these lymphocytes are recruited in this pathological setting remains unclear. Here, we analyzed 17 DSPTC cases immunohistologically for cell adhesion molecules expressed on endothelial cells. We found that venules morphologically similar to high endothelial venules (HEVs) in secondary lymphoid organs were induced in lymphoid aggregates in DSPTC, and such HEV-like vessels expressed 6-sulfo sialyl Lewis X (sLeX) glycans as well as intercellular adhesion molecule 1 (ICAM-1). Triple immunohistochemistry revealed that $\mathrm{CD} 8^{+}$cytotoxic $\mathrm{T}$ cells were the major lymphocyte subset attached to the luminal surface of HEV-like vessels. sLeX-type glycans were also expressed on DSPTC carcinoma cells, which in binding assays were decorated with E-selectin॰IgM chimeras calcium-dependently. These findings collectively suggest that 6 -sulfo sLeX glycans, together with ICAM-1, on HEV-like vessels may function to recruit CD8 ${ }^{+}$ cytotoxic T cells in DSPTC. Additionally, sLeX-type glycans on carcinoma cells might partly contribute to highly metastatic properties of DSPTC through interaction with E-selectin expressed on endothelial cells.

Key words: cytotoxic T lymphocyte, diffuse sclerosing variant of papillary thyroid carcinoma (DSPTC), high endothelial venule (HEV)-like vessels, intercellular cell adhesion molecule 1 (ICAM-1), lymphocyte recruitment, 6-sulfo sialyl Lewis X (sLeX) 


\section{INTRODUCTION}

Papillary carcinoma is the most common type of thyroid carcinoma and represents $80-90 \%$ of all primary thyroid malignancies. ${ }^{1} \quad$ Several morphological variants of papillary thyroid carcinoma (PTC) are well-recognized, and among them, diffuse sclerosing variant of PTC (DSPTC), which predominantly affects young women, is a relatively rare variant with a high incidence of cervical lymph node metastasis. ${ }^{2-5}$ DSPTC is characterized histologically by scattered islands of papillary carcinoma nests, with occasional squamous metaplasia and psammoma body formation, in cleft-like dilated lymphatic vessels. These regions also exhibit dense stromal fibrosis, and marked lymphocytic infiltrates with occasional germinal center formation reminiscent of Hashimoto's thyroiditis. ${ }^{2,3,5}$

Under chronic inflammatory states such as Hashimoto's thyroiditis, venules morphologically similar to high endothelial venules (HEVs) in secondary lymphoid organs are induced at inflammatory sites. ${ }^{6,7}$ HEVs play a central role in physiological lymphocyte recirculation, termed lymphocyte "homing", ${ }^{\text {a }}$ multi-step process requiring interplay of cell adhesion molecules on HEVs with counter-receptors on lymphocytes. ${ }^{9} \quad$ For the initial step, L-selectin expressed on lymphocytes interacts with its carbohydrate ligand 6-sulfo sialyl Lewis X (sLeX) glycans on HEVs, resulting in tethering and rolling of lymphocytes along the luminal HEV surface. ${ }^{10-12}$ After activation of lymphocytes by chemokines such as CCL19 and CCL21, lymphocyte integrins $\alpha_{L} \beta_{2}, \alpha_{4} \beta_{1}$ and $\alpha_{4} \beta_{7}$ interact with their cell adhesion counter-receptors of the immunoglobulin superfamily, namely, intercellular adhesion molecule 1 (ICAM-1), vascular cell adhesion molecule 1 (VCAM-1) and mucosal addressin cell adhesion molecule 1 (MAdCAM-1), respectively, to initiate firm attachment of lymphocytes to endothelium. ${ }^{13}$ Eventually, lymphocytes extravasate through HEVs and migrate to appropriate lymph node compartments driven by chemokine attraction and stimulation. ${ }^{14}$

Previously, we demonstrated that HEV-like vessels are induced in chronic inflammatory conditions, such as chronic Helicobacter pylori gastritis, ${ }^{15-17}$ inflammatory bowel diseases ${ }^{18,19}$ and autoimmune pancreatitis, ${ }^{20}$ as well as in lymphoid stroma formed in certain 
types of tumors, such as salivary Warthin's tumor ${ }^{21}$ and testicular seminoma. ${ }^{22}$ Such HEV-like vessels reportedly play a role in lymphocyte recruitment in a manner similar to HEVs in secondary lymphoid organs. ${ }^{7,23-25}$ Moreover, Martinet et al. recently reported that HEV-like vessels are induced in lymphocyte-rich areas of breast carcinoma, and that vessel density was positively correlated with favorable prognosis. ${ }^{26}$

Here we show that HEV-like vessels are induced in dense lymphocyte infiltrates formed in DSPTC. We observed that lymphocytes, primarily $\mathrm{CD}^{+}$cytotoxic $\mathrm{T}$ cells, attach to the luminal surface of these vessels, suggesting that a subset of lymphocytes constituting DSPTC lymphoid stroma is recruited via these vessels. We also found that sLeX-type glycans, which function as E-selectin ligands, are expressed on DSPTC carcinoma cells, raising the possibility that sLeX-type glycans expressed on tumor cells might function in cancer metastasis. 


\section{MATERIALS AND METHODS}

\section{Tissue samples}

Formalin-fixed, paraffin-embedded tissue blocks of surgical specimens of thyroid with DSPTC ( $n$ =17) were retrieved from the pathological archives of the Department of Diagnostic Pathology, Kuma Hospital, Kobe, Japan. Clinicopathological features of all cases are shown in Table 1. Thyroid tissue blocks derived from patients with Hashimoto's thyroiditis $(n=3)$ and the Warthin-like variant of PTC (WLPTC) $(n=3)$ were also retrieved as controls. Analysis of human tissues was approved by the Ethics Committee of the Faculty of Medical Sciences, University of Fukui (reference No. 26-59, approved on July 28, 2014).

\section{Antibodies}

Primary antibodies used in this study were as follows: MECA-79, recognizing 6-sulfo $\mathrm{N}$-acetyllactosamine (LacNAc) attached to extended core $1 O$-glycans, regardless of galactose (Gal)- $\alpha 2,3$-sialylation and/or $N$-acetylglucosamine (GlcNAc)- $\alpha 1,3$-fucosylation (BD Pharmingen, San Diego, CA); ${ }^{27,28}$ HECA-452, recognizing sLeX regardless of GlcNAc-6- $O$-sulfation (BD Pharmingen); ${ }^{29} \mathrm{~S} 1$, recognizing sialylated 6-sulfo LacNAc, regardless of GlcNAc- $\alpha 1,3$-fucosylation; ${ }^{30}$ rabbit polyclonal anti-human ICAM-1 (Atlas Antibodies, Stockholm, Sweden); EPR5047 for human VCAM-1 (Abcam, Cambridge, UK); \#15-8G-61 antibody generated in our laboratory for human MAdCAM-1; ${ }^{17}$ L26 for human CD20 (Dako, Glostrup, Denmark); JCB117 for human CD79a (Dako); rabbit polyclonal anti-human CD3 (Dako); 1F6 for human CD4 (Leica Biosystems, Newcastle Upon Tyne, UK); and C8/144B for human CD8 (Dako).

\section{Immunohistochemistry and immunofluorescence}

Conventional immunohistochemistry for MECA-79, HECA-452 and S1 was conducted as described. $^{30}$ Double immunofluorescence for MECA-79 and either ICAM-1, VCAM-1 or MAdCAM-1 was performed as described. ${ }^{22}$ Triple immunohistochemistry was carried out 
essentially as described. ${ }^{22}$ Briefly, after antigen retrieval and blocking, tissue sections were incubated with antibodies for CD3 or CD4 followed by incubation with Histofine Simple Stain AP (Nichirei, Tokyo, Japan). The color reaction was developed using a Ferangi Blue Chromogen Kit 2 (Biocare Medical, Concord, CA). After boiling in Tris/EDTA solution, sections were incubated with CD20/CD79a or CD8 antibodies and then incubated with Histofine Simple Stain AP. The color reaction was developed using a Vulcan Fast Red Chromogen Kit 2 (Biocare Medical). After boiling them again in Tris/EDTA solution and quenching endogenous peroxidase activity, sections were incubated with MECA-79 and then with horseradish peroxidase (HRP)-conjugated rabbit anti-rat immunoglobulins (Dako). The color reaction was developed with 3,3'-diaminobenzidine (DAB). Negative controls were obtained by replacing primary antibodies with isotype-matched immunoglobulins.

\section{Quantification of lymphocyte subsets attached to HEV-like vessels}

For each lymphocyte subset, we determined the number of cells attached to the luminal surface of 50 randomly selected MECA-79 $\mathrm{HEV}$-like vessels in specimens of each of the 17 DSPTC cases. In total, $850 \mathrm{MECA}-79^{+} \mathrm{HEV}$-like vessels were evaluated, and the mean number of attached cells per vessel was calculated as described. ${ }^{21}$ The number of cells in each lymphocyte subset in Hashimoto's thyroiditis specimens was similarly determined.

\section{E-selectin•IgM chimera in situ binding assay}

E-selectin॰IgM chimeras were obtained from the culture medium of COS-7 cells transiently transfected with pcDNA1.1-E-selectin $\cdot \operatorname{IgM} .^{31} \quad$ An E-selectin•IgM chimera in situ binding assay was carried out as described. ${ }^{15}$

\section{Statistical analysis}

Data are expressed as means \pm standard deviation (SD). Differences between groups were statistically analyzed by the two-tailed paired $t$-test using GraphPad Prism 5 software (GraphPad 
Software, La Jolla, CA). $\quad p$ values less than 0.05 were considered significant. 


\section{RESULTS}

\section{Induction of HEV-like vessels in DSPTC lymphocyte aggregates}

The cohort of DSPTC cases examined for this study $(n=17)$ showed strong female predominance (female: male ratio $=16: 1$ ), and patient ages at the time of operation ranged from 13 to 53 years, with a median of 29 years. These observations are consistent with reports that DSPTC occurs mainly in young women. ${ }^{2-5}$ Additionally, all 17 DSPTC cases exhibited lymphatic invasion and consequent lymph node metastasis, while vascular invasion was not evident by microscopic examination and only two cases showed distant metastasis to the lung (Table 1). Histologically, all cases examined showed characteristics of DSPTC. As shown in Fig. 1, scattered islands of papillary carcinoma nests, with or without psammoma bodies and squamous metaplasia, were found within cleft-like dilated lymphatic vessels. Those vessels were surrounded by prominent fibrous stroma with patchy lymphocyte aggregates accompanied by germinal centers. Within aggregates, venules morphologically similar to HEVs in secondary lymphoid organs were frequently observed in all cases examined (Fig. 2, upper panels). Similar vessels were also observed within lymphoid aggregates in Hashimoto's thyroiditis (Fig. 2, middle

panels), as previously reported, ${ }^{6}$ but were scarcely detectable in WLPTC lymphoid stroma (Fig. 2, lower panels).

\section{Expression of 6-sulfo sLeX glycans on DSPTC HEV-like vessels}

We then performed immunohistochemical analysis of glycans expressed on HEV-like vessels seen in DSPTC, along with those seen in Hashimoto's thyroiditis and WLPTC. As shown in Fig. 2 (upper panels), the luminal surface of DSPTC HEV-like vessels stained positive for both MECA-79 and S1, and approximately half of these vessels were also HECA-452-positive. HEV-like vessels induced in Hashimoto's thyroiditis showed similar immunohistochemical profiles (Fig. 2, middle panels). Interestingly, however, only a few, fine MECA-79-positive vessels were observed in WLPTC lymphoid stroma, and those were HECA-452- and S1-negative (Fig. 2, lower panels). Considering the carbohydrate epitopes recognized by these antibodies 
(Fig. 3), ${ }^{32}$ these results strongly suggest that HEV-like vessels induced in DSPTC and Hashimoto's thyroiditis express 6-sulfo sLeX glycans and thus may function in the initial step of lymphocyte recruitment, namely, L-selectin-mediated tethering and rolling of lymphocytes along endothelium. On the other hand, fine MECA- $79^{+}$vessels seen in WLPTC likely express non-sialylated, non-fucosylated incomplete L-selectin ligand carbohydrates, such as 6-sulfo LacNAc attached to extended core $1 O$-glycans.

\section{Expression of ICAM-1 on HEV-like vessels and on DSPTC carcinoma cells}

To determine which cell adhesion molecule of the immunoglobulin superfamily is expressed on vessels that express 6-sulfo sLeX glycans, we conducted double immunofluorescence staining for MECA-79 plus either ICAM-1, VCAM-1 or MAdCAM-1. MECA-79 ${ }^{+}$HEV-like vessels in DSPTC (Fig. 4) and Hashimoto's thyroiditis (Fig. 5) were positive for ICAM-1 but not for VCAM-1 or MAdCAM-1. On the other hand, none of the three adhesion proteins tested was expressed on fine MECA-79 ${ }^{+}$vessels seen in WLPTC (Fig. 6). These findings indicate that, in DSPTC and Hashimoto's thyroiditis, 6-sulfo sLeX glycans and ICAM-1 are co-expressed on HEV-like vessels and suggests that ICAM-1 likely functions in the arrest step of lymphocyte recruitment, specifically in firm attachment of lymphocytes to endothelium. ICAM-1 was also expressed on numerous carcinoma cells in DSPTC (Fig. 7) and WLPTC (Fig. 6, top panels) samples, consistent with previous reports. ${ }^{33}$

\section{Close association of $\mathrm{CD8}^{+}$cytotoxic T cells with DSPTC HEV-like vessels}

We then asked which lymphocyte subset is more closely associated with DSPTC HEV-like vessels. To do so, we first undertook triple immunohistochemistry for CD3 (for T cells) and CD20/CD79a (for B cells), together with MECA-79 (Fig. 8A, left panel), and counted the number of respective $\mathrm{T}$ and $\mathrm{B}$ cells attached to the luminal surface of MECA-79 $\mathrm{HEV}$-like vessels. The number of $T$ cells attached per HEV-like vessel $(0.83 \pm 0.31)$ exceeded that of $B$ cells $(0.24 \pm 0.11)$ with high statistical significance $(p<0.001)$ (Fig. 8B, left panel). We then 
focused primarily on $\mathrm{T}$ cells and performed triple immunohistochemistry for CD4 (for helper T cells) and CD8 (for cytotoxic T cells), together with MECA-79 (Fig. 8A, right panel). We found that the number of $\mathrm{CD} 8^{+}$cytotoxic $\mathrm{T}$ cells attached per HEV-like vessel $(0.49 \pm 0.11)$ was greater than that of $\mathrm{CD}^{+}$helper T cells $(0.21 \pm 0.07)$ with high statistical significance $(p<0.001)$ (Fig. 8B, right panel). We also evaluated lymphocyte subsets in Hashimoto's thyroiditis. Similar to DSPTC, the number of $\mathrm{T}$ cells attached to vessels $(0.70 \pm 0.24)$ exceeded the number of $\mathrm{B}$ cells $(0.39 \pm 0.07)$, but that difference was not statistically significant $(p=0.2803)$. Also, the number of $\mathrm{CD}^{+}{ }^{+}$helper $\mathrm{T}$ cells $(0.35 \pm 0.07)$ and $\mathrm{CD} 8^{+}$cytotoxic $\mathrm{T}$ cells $(0.39 \pm 0.15)$ attached to vessels did not differ significantly $(p=0.9110)$. In WLPTC, the number of lymphocyte subsets attached to vessels could not be determined because i) very few fine MECA- $79^{+}$vessels were seen in lymphoid tumor stroma, and ii) few lymphocytes were found in the narrow, slit-like lumina of fine MECA- $79^{+}$vessels. These findings indicate overall that $\mathrm{T}$ cells, particularly $\mathrm{CD} 8^{+}$cytotoxic $\mathrm{T}$ cells, are more closely associated with HEV-like vessels induced in DSPTC, suggesting that cytotoxic $\mathrm{T}$ cells are likely recruited via these vessels.

\section{Expression of sLeX-type glycans on DSPTC carcinoma cells}

In addition to their expression on HEV-like vessels, we found that HECA- $452^{+}$sLeX-type glycans are expressed on most DSPTC carcinoma cells (Fig. 9, upper panels). Interestingly, a fraction of those HECA-452 ${ }^{+}$carcinoma cells was also positive for MECA-79 (see also Fig. 7) and/or S1, strongly suggesting that sLeX-type glycans expressed on DSPTC carcinoma cells include both non-sulfated and 6-sulfo sLeX glycans. HECA-452 ${ }^{+}$sLeX-type glycans were also expressed on WLPTC carcinoma cells; however, expression of MECA-79 and/or S1 glycoepitopes was hardly detectable in any case examined (Fig. 9, lower panels; see also Fig. 2, lower panels). Conversely, non-neoplastic follicular epithelial cells, including those seen in Hashimoto's thyroiditis, completely lacked these glycans (Fig. 9, middle panels). To determine whether sLeX-type glycans expressed on DSPTC carcinoma cells function as E-selectin ligands, we conducted an E-selectin•IgM chimera in situ binding assay using DSPTC tissue sections. 
E-selectin•IgM chimeras bound to carcinoma cells (Fig. 10), and binding was completely abolished in the presence of EDTA, that is in the absence of calcium ions. Overall, these findings indicate that sLeX-type glycans expressed on DSPTC carcinoma cells are functional E-selectin ligands and may facilitate carcinoma cell adhesion to E-selectin-expressing endothelial cells, a prerequisite for metastasis. 


\section{DISCUSSION}

In the present study, we demonstrate that HEV-like vessels that express 6-sulfo sLeX glycans and ICAM-1 are induced in lymphocyte aggregates formed not only in Hashimoto's thyroiditis but also in DSPTC. Moreover, we show that $\mathrm{T}$ cells, particularly $\mathrm{CD} 8^{+}$cytotoxic $\mathrm{T}$ cells, become preferentially attached to the luminal surface of these vessels. Overall, these findings strongly suggest that HEV-like vessels play at least a partial role in recruitment of $\mathrm{CD} 8^{+}$cytotoxic $\mathrm{T}$ cells to lymphocyte aggregates formed in DSPTC.

In our analysis, we employed three different clones of anti-carbohydrate monoclonal antibodies, namely, MECA-79, HECA-452 and S1, whose carbohydrate epitopes overlap with 6-sulfo sLeX glycans, an L-selectin recognition determinant (see Fig. 3). ${ }^{24,32}$ As noted, HEV-like vessels induced in DSPTC expressed MECA-79 and S1 epitopes; however, approximately one half of those MECA-79/S1-positive vessels lacked HECA-452 immunoreactivity. This finding is in line with our previous studies of chronic Helicobacter pylori gastritis ${ }^{15,16}$ and ulcerative colitis ${ }^{18}$ both of which demonstrated that approximately half of HEV-like vessels were HECA-452-negative. Overall, these observations suggest that $\alpha 1,3$-fucosylation of GlcNAc residues in the sLeX moiety, which is critical for recognition by HECA-452, does not always occur in HEV-like vessels induced in these pathological settings. It is possible that fucosylation, which is elaborated by $\alpha 1,3$-fucosyltransferase 4 and/or $7,34,35$ modulates the number of lymphocytes recruited through HEV-like vessels.

Interestingly, unlike DSPTC and Hashimoto's thyroiditis, only a small number of fine MECA- $79^{+}$vessels were observed in WLPTC lymphoid stroma, and these lacked S1 or HECA-452 immunoreactivity, strongly suggesting that these vessels express incomplete L-selectin ligands, most likely 6-sulfo LacNAc attached to extended core $1 O$-glycans. Moreover, these vessels did not exhibit detectable levels of any immunoglobulin superfamily cell adhesion molecule tested. These findings collectively suggest that i) mechanisms underlying lymphocyte recruitment in DSPTC are similar to those in Hashimoto's thyroiditis, and ii) mechanisms underlying lymphocyte recruitment in WLPTC differ and are unique. 
Among cell adhesion molecules of the immunoglobulin superfamily, only ICAM-1 was expressed on HEV-like vessels in DSPTC and Hashimoto's thyroiditis. ICAM-1 is reportedly constitutively expressed on endothelial cells, thymic epithelial cells, macrophages and activated lymphocytes. $^{36}$ In addition to its physiological expression on HEV-like vessels, ICAM-1 is aberrantly reportedly expressed on PTC cells, ${ }^{33}$ a finding in accord with those reported here. Previous studies revealed that ICAM-1 expression on carcinoma cells facilitates their adhesion to the vascular endothelium and is correlated with malignant phenotypes, including lymph node metastasis. $33,37,38$ The same mechanism might contribute in part to the highly metastatic property of DSPTC.

Molecular mechanisms that underlie induction of HEV-like vessels in DSPTC remain to be elucidated. Chou et al. reported that $A L K$ translocations frequently serve as driver mutations in DSPTC. ${ }^{39}$ They also found that $36 \%$ of PTC samples exhibiting ALK translocations showed histological evidence of Hashimoto's thyroiditis. ${ }^{39}$ These observations collectively suggest a link between $A L K$ translocations and induction of HEV-like vessels, although further investigations are required for confirmation. BRAF mutations are considered to be driver mutations in roughly $50 \%$ of PTC cases. $^{40}$ Because the latter are detected not only in WLPTC but in other PTC variants without lymphoid aggregates, ${ }^{41}$ it is reasonable to assume that $B R A F$ mutations are not directly responsible for formation of HEV-like vessels.

As noted, $\mathrm{CD}^{+}$cytotoxic $\mathrm{T}$ cells were the dominant lymphocyte subset attached to the luminal surface of DSPTC HEV-like vessels. While we observed no significant difference in the number of attached B and T cells in our small cohort of Hashimoto's thyroiditis samples, previous studies reported that B cells attach preferentially to HEV-like vessels in Hashimoto's thyroiditis. ${ }^{6}$ Such differential lymphocyte binding capacities of HEV-like vessels in different pathological settings may be orchestrated by different chemokines acting on these vessels. It is tempting to speculate that, in the case of DSPTC, CCL19 and/or CCL21 facilitate adhesion of T cells to HEV-like vessels through interaction with the CCR7 chemokine receptor expressed on T cells, ${ }^{42,43}$ while CXCL13, which binds to CXCR5 on B cells, may promote preferential adhesion 
of B cells to HEV-like vessels in Hashimoto's thyroiditis. ${ }^{44}$ It is also possible that vascular adhesion protein 1 (VAP-1), which mediates L-selectin-independent selective binding of $\mathrm{CD}^{+} \mathrm{T}$ cells to endothelial cells, ${ }^{45}$ functions in preferential adhesion of $\mathrm{CD}^{+} \mathrm{T}$ cells in DSPTC.

In the present study, we also demonstrate that HECA- $452^{+}$sLeX-type glycans are expressed not only on HEV-like vessels but also on DSPTC carcinoma cells and that, in binding assays these carcinoma cells become decorated with E-selectin•IgM chimeras in a calcium-dependent fashion. These sLeX-type glycans include both non-sulfated and 6-sulfo sLeX, and both are physiologically expressed on HEVs and HEV-like vessels. ${ }^{11}$ Aberrant expression of 6-sulfo sLeX glycans has been reported in ovarian ${ }^{46}$ and gastric $^{47}$ carcinomas. $^{2}$ Recently, we also reported that 6-sulfo sLeX glycans are expressed in a fraction of bladder urothelial carcinoma cases and showed that carcinoma cells expressing these glycans were decorated with E-selectin•IgM chimeras calcium-dependently in binding assays. ${ }^{48}$ Taken together, these findings suggest that sLeX-type glycans expressed on DSPTC carcinoma cells may function in adhesion between carcinoma cells and E-selectin-expressing lymphatic endothelial cells, ${ }^{49}$ an interaction that might contribute in part to significant lymphogenous spreading and subsequent lymph node metastasis that marks DSPTC.

Tumor cell recruitment from the primary site into lymphatic vessels, or lymphatic intravasation, is also prerequisite for development of lymph node metastasis, and several factors, including transforming growth factor $\beta$ (TGF- $\beta),{ }^{50}$ receptor tyrosine kinases ${ }^{51}$ and proteases ${ }^{52,53}$, reportedly function in this process. ${ }^{54}$ Among these, it is generally accepted that proteases such as urokinase-type plasminogen activator ${ }^{52}$ and matrix metalloproteinases ${ }^{53}$ allow tumor cells to invade and pass through the basement membrane to enter the lymphatic vessels. ${ }^{54}$ The sLeX-type glycans shown here to be expressed on DSPTC cells likely do not contribute to this intravasation step, because their ligand E-selectin is not expressed on the abluminal aspect of lymphatic vessels. Thus, it is possible that proteases such as matrix metalloproteinases may function in intravasation of DSPTC carcinoma cells. Further studies are, however, necessary to support this hypothesis. 
Acknowledgements: We thank Mr. Naoki Yamao and Ms. Noriko Maruta for technical assistance, Ms. Risa Kanamori for assisting quantitative histological analysis, and Dr. Elise Lamar for critical reading of the manuscript. Part of the work was presented as a poster at the annual meeting of the Japanese Society for Immunology, held in Sapporo, Japan, November 18-20, 2015. 


\section{References}

1. Regalbuto $\mathrm{C}$, Malandrino $\mathrm{P}$, Tumminia A, et al. A diffuse sclerosing variant of papillary thyroid carcinoma: clinical and pathologic features and outcomes of 34 consecutive cases. Thyroid 2011; 21: 383-9.

2. Fujimoto Y, Obara T, Ito Y, et al. Diffuse sclerosing variant of papillary carcinoma of the thyroid. Clinical importance, surgical treatment, and follow-up study. Cancer 1990; 66: 2306-12.

3. Chow SM, Chan JK, Law SC, et al. Diffuse sclerosing variant of papillary thyroid carcinoma-clinical features and outcome. Eur J Surg Oncol 2003; 29: 446-9.

4. Thompson LD, Wieneke JA, Heffess CS. Diffuse sclerosing variant of papillary thyroid carcinoma: a clinicopathologic and immunophenotypic analysis of 22 cases. Endocr Pathol 2005; 16: 331-48.

5. Lam AK, Lo CY. Diffuse sclerosing variant of papillary carcinoma of the thyroid: a 35-year comparative study at a single institution. Ann Surg Oncol 2006; 13: 176-81.

6. Kabel PJ, Voorbij HA, de Haan-Meulman M, et al. High endothelial venules present in lymphoid cell accumulations in thyroids affected by autoimmune disease: a study in men and BB rats of functional activity and development. J Clin Endocrinol Metab 1989; 68: 744-51.

7. Aloisi F, Pujol-Borrell R. Lymphoid neogenesis in chronic inflammatory diseases. Nat Rev Immunol 2006; 6: 205-17.

8. von Andrian UH, Mempel TR. Homing and cellular traffic in lymph nodes. Nat Rev Immunol 2003; 3: 867-78.

9. Butcher EC, Picker LJ. Lymphocyte homing and homeostasis. Science 1996; 272: 60-6.

10. Uchimura K, Kadomatsu K, El-Fasakhany FM, et al. $N$-acetylglucosamine 6-O-sulfotransferase-1 regulates expression of L-selectin ligands and lymphocyte homing. $J$ Biol Chem 2004; 279: 35001-8.

11. Kawashima H, Petryniak B, Hiraoka N, et al. $\mathrm{N}$-acetylglucosamine-6- $O$-sulfotransferases 1 and 2 cooperatively control lymphocyte homing through L-selectin ligand biosynthesis in 
high endothelial venules. Nat Immunol 2005; 6: 1096-104.

12. Uchimura K, Gauguet JM, Singer MS, et al. A major class of L-selectin ligands is eliminated in mice deficient in two sulfotransferases expressed in high endothelial venules. Nat Immunol 2005; 6: 1105-13.

13. Springer TA. Traffic signals for lymphocyte recirculation and leukocyte emigration: the multistep paradigm. Cell 1994; 76: 301-14.

14. Girard JP, Moussion C, Förster R. HEVs, lymphatics and homeostatic immune cell trafficking in lymph nodes. Nat Rev Immunol 2012; 12: 762-73.

15. Kobayashi M, Mitoma J, Nakamura N, et al. Induction of peripheral lymph node addressin in human gastric mucosa infected by Helicobacter pylori. Proc Natl Acad Sci USA 2004; 101: 17807-12.

16. Kobayashi M, Mitoma J, Hoshino H, et al. Prominent expression of sialyl Lewis X-capped core 2-branched $O$-glycans on high endothelial venule-like vessels in gastric MALT lymphoma. J Pathol 2011; 224: 67-77.

17. Okamura T, Sakai Y, Hoshino H, et al. Superficially located enlarged lymphoid follicles characterise nodular gastritis. Pathology 2015; 47: 38-44.

18. Suzawa K, Kobayashi M, Sakai Y, et al. Preferential induction of peripheral lymph node addressin on high endothelial venule-like vessels in the active phase of ulcerative colitis. Am J Gastroenterol 2007; 102: 1499-509.

19. Kobayashi M, Hoshino H, Masumoto J, et al. GlcNAc6ST-1-mediated decoration of MAdCAM-1 protein with L-selectin ligand carbohydrates directs disease activity of ulcerative colitis. Inflamm Bowel Dis 2009; 15: 697-706.

20. Maruyama M, Kobayashi M, Sakai Y, et al. Periductal induction of high endothelial venule-like vessels in type 1 autoimmune pancreatitis. Pancreas 2013; 42: 53-9.

21. Ohya A, Kobayashi M, Sakai Y, et al. Lymphocyte recruitment via high endothelial venules in lymphoid stroma of Warthin's tumour. Pathology 2013; 45: 150-4.

22. Sakai Y, Hoshino H, Kitazawa R, et al. High endothelial venule-like vessels and lymphocyte 
recruitment in testicular seminoma. Andrology 2014; 2: 282-9.

23. Drayton DL, Liao S, Mounzer RH, et al. Lymphoid organ development: from ontogeny to neogenesis. Nat Immunol 2006; 7: 344-53.

24. Uchimura K, Rosen SD. Sulfated L-selectin ligands as a therapeutic target in chronic inflammation. Trends Immunol 2006; 27: 559-65.

25. Sakai Y, Kobayashi M. Lymphocyte 'homing' and chronic inflammation. Pathol Int 2015; 65: $344-54$.

26. Martinet L, Garrido I, Filleron T, et al. Human solid tumors contain high endothelial venules: association with T- and B-lymphocyte infiltration and favorable prognosis in breast cancer. Cancer Res 2011; 71: 5678-87.

27. Streeter PR, Rouse BT, Butcher EC. Immunohistologic and functional characterization of a vascular addressin involved in lymphocyte homing into peripheral lymph nodes. J Cell Biol 1988; 107: 1853-62.

28. Yeh JC, Hiraoka N, Petryniak B, et al. Novel sulfated lymphocyte homing receptors and their control by a core 1 extension $\beta 1,3-N$-acetylglucosaminyltransferase. Cell 2001; 105: 957-69.

29. Picker LJ, Michie SA, Rott LS, et al. A unique phenotype of skin-associated lymphocytes in humans. Preferential expression of the HECA-452 epitope by benign and malignant T cells at cutaneous sites. Am J Pathol 1990; 136: 1053-68.

30. Hirakawa J, Tsuboi K, Sato K, et al. Novel anti-carbohydrate antibodies reveal the cooperative function of sulfated $N$ - and $O$-glycans in lymphocyte homing. J Biol Chem 2010; 285: 40864-78.

31. Hiraoka N, Kawashima H, Petryniak B, et al. Core 2 branching $\beta 1,6-N$-acetylglucosaminyltransferase and high endothelial venule-restricted sulfotransferase collaboratively control lymphocyte homing. J Biol Chem 2004; 279: 3058-67.

32. Kobayashi M, Hoshino H, Suzawa K, et al. Two distinct lymphocyte homing systems involved in the pathogenesis of chronic inflammatory gastrointestinal diseases. Semin Immunopathol 2012; 34: 401-13. 
33. Buitrago D, Keutgen XM, Crowley M, et al. Intercellular adhesion molecule-1 (ICAM-1) is upregulated in aggressive papillary thyroid carcinoma. Ann Surg Oncol 2012; 19: 973-80.

34. Malý P, Thall A, Petryniak B, et al. The $\alpha(1,3)$ fucosyltransferase Fuc-TVII controls leukocyte trafficking through an essential role in L-, E-, and P-selectin ligand biosynthesis. Cell 1996; 86: $643-53$.

35. Homeister JW, Thall AD, Petryniak B, et al. The $\alpha(1,3)$ fucosyltransferases FucT-IV and FucT-VII exert collaborative control over selectin-dependent leukocyte recruitment and lymphocyte homing. Immunity 2001; 15: 115-26.

36. Dustin ML, Rothlein R, Bhan AK, et al. Induction by IL 1 and interferon- $\gamma$ : tissue distribution, biochemistry, and function of a natural adherence molecule (ICAM-1). J Immunol 1986; 137: 245-54.

37. Steinbach F, Tanabe K, Alexander J, et al. The influence of cytokines on the adhesion of renal cancer cells to endothelium. J Urol 1996; 155: 743-8.

38. Schröder C, Witzel I, Müller V, et al. Prognostic value of intercellular adhesion molecule (ICAM)-1 expression in breast cancer. J Cancer Res Clin Oncol 2011; 137: 1193-201.

39. Chou A, Fraser S, Toon CW, et al. A detailed clinicopathologic study of ALK-translocated papillary thyroid carcinoma. Am J Surg Pathol 2015; 39: 652-9.

40. Finkelstein A, Levy GH, Hui P, et al. Papillary thyroid carcinomas with and without BRAF V600E mutations are morphologically distinct. Histopathology 2012; 60: 1052-9.

41. Yeo MK, Bae JS, Lee S, et al. The Warthin-like variant of papillary thyroid carcinoma: a comparison with classic type in the patients with coexisting Hashimoto's thyroiditis. Int $J$ Endocrinol 2015; 2015: 456027.

42. Yoshida R, Nagira M, Kitaura M, et al. Secondary lymphoid-tissue chemokine is a functional ligand for the CC chemokine receptor CCR7. J Biol Chem 1998; 273: 7118-22.

43. Bromley SK, Thomas SY, Luster AD. Chemokine receptor CCR7 guides T cell exit from peripheral tissues and entry into afferent lymphatics. Nat Immunol 2005; 6: 895-901.

44. Gunn MD, Ngo VN, Ansel KM, et al. A B-cell-homing chemokine made in lymphoid 
follicles activates Burkitt's lymphoma receptor-1. Nature 1998; 391: 799-803.

45. Salmi M, Hellman J, Jalkanen S. The role of two distinct endothelial molecules, vascular adhesion protein-1 and peripheral lymph node addressin, in the binding of lymphocyte subsets to human lymph nodes. J Immunol 1998; 160: 5629-36.

46. Kanoh A, Seko A, Ideo $\mathrm{H}$, et al. Ectopic expression of $\mathrm{N}$-acetylglucosamine 6-O-sulfotransferase 2 in chemotherapy-resistant ovarian adenocarcinomas. Glycoconj $J$ 2006; 23: 453-60.

47. Okayama H, Kumamoto K, Saitou K, et al. Ectopic expression of MECA-79 as a novel prognostic indicator in gastric cancer. Cancer Sci 2011; 102: 1088-94.

48. Taga M, Hoshino H, Low S, et al. A potential role for 6-sulfo sialyl Lewis X in metastasis of bladder urothelial carcinoma. Urol Oncol 2015; 33: 496.e1-9.

49. Johnson LA, Clasper S, Holt AP, et al. An inflammation-induced mechanism for leukocyte transmigration across lymphatic vessel endothelium. J Exp Med 2006; 203: 2763-77.

50. Muraoka RS, Dumont N, Ritter CA, et al. Blockade of TGF- $\beta$ inhibits mammary tumor cell viability, migration, and metastases. J Clin Invest 2002; 109: 1551-9.

51. Xue C, Wyckoff J, Liang F et al. Epidermal growth factor receptor overexpression results in increased tumor cell motility in vivo coordinately with enhanced intravasation and metastasis. Cancer Res 2006; 66: 192-7.

52. Ossowski L. Plasminogen activator dependent pathways in the dissemination of human tumor cells in the chick embryo. Cell 1988; 52: 321-3.

53. Juncker-Jensen A, Deryugina EI, Rimann I, et al. Tumor MMP-1 activates endothelial PAR1 to facilitate vascular intravasation and metastatic dissemination. Cancer Res 2013; 73: 4196-211.

54. Chiang SP, Cabrera RM, Segall JE. Tumor cell intravasation. Am J Physiol Cell Physiol 2016; 311: C1-14. 


\section{Figure Legends}

Fig 1. Representative histology of DSPTC specimens. (Left panel) Cleft-like dilated lymph vessels are packed with papillary carcinoma nests (arrow), and these lymph vessels are surrounded by dense fibrotic stroma with patchy lymphocyte aggregates (arrowhead). (Right panel) Lymphocyte aggregates are occasionally accompanied by germinal center formation (arrow). Note that psammoma bodies (arrowhead) and squamous metaplasia (asterisk) are observed. Hematoxylin and eosin staining. Bar $=500 \mu \mathrm{m}$ for left panel and $200 \mu \mathrm{m}$ for right panel.

Fig 2. Immunohistochemical profiles of HEV-like vessels induced in DSPTC (upper panels), Hashimoto's thyroiditis (HT) (middle panels) and WLPTC (lower panels). Serial tissue sections were subjected to immunohistochemistry for MECA-79, HECA-452 and S1. Note that HECA $-452^{+}$cells in WLPTC are carcinoma cells, not endothelial cells (row 3, second right panel). Signals were visualized with DAB (brown). All panels are counterstained with hematoxylin; left panels are stained with hematoxylin and eosin $(\mathrm{HE}) . \quad$ Bar $=50 \mu \mathrm{m}$.

Fig 3. Carbohydrate structure of an L-selectin ligand, 6-sulfo sLeX attached to both extended core 1 and core 2-branched $O$-glycans. Epitopes are shown for MECA-79 (6-sulfo LacNAc attached to extended core $1 O$-glycans, regardless of Gal- $\alpha 2,3$-sialylation and/or GlcNAc- $\alpha 1$,3-fucosylation), HECA-452 (sLeX, regardless of GlcNAc-6-O-sulfation) and S1 (sialylated 6-sulfo LacNAc, regardless of GlcNAc- $\alpha 1,3$-fucosylation) antibodies. SA, sialic acid; Fuc, fucose; Gal, galactose; GlcNAc, $N$-acetylglucosamine; GalNAc, $N$-acetylgalactosamine. Based on ref. 32.

Fig 4. Double immunofluorescence of DSPTC specimen sections for MECA-79 (green) and a battery of cell adhesion molecules (CAMs) of the immunoglobulin superfamily (red). 6-sulfo sLeX glycan expression (green) co-localizes with that of ICAM-1 (red) on HEV-like vessels, as 
indicated by yellow signals in merged images (row 1, right panel). VCAM-1 and MAdCAM-1 are not expressed on HEV-like vessels. Note that VCAM-1 is expressed on meshwork of follicular dendritic cells (row 2, middle and right panels).

Fig 5. Double immunofluorescence of sections from Hashimoto's thyroiditis specimens for MECA-79 (green) and a battery of cell adhesion molecules (CAMs) of the immunoglobulin superfamily (red). 6-sulfo sLeX glycan expression (green) co-localizes with that of ICAM-1 (red) on HEV-like vessels, as indicated by yellow signals in merged images (row 1, right panel). VCAM-1 and MAdCAM-1 are not expressed on HEV-like vessels. Red signals within vessels represent red blood cell autofluorescence. $B a r=50 \mu \mathrm{m}$.

Fig 6. Double immunofluorescence of sections of WLPTC specimens for MECA-79 (green) and a battery of cell adhesion molecules (CAMs) of the immunoglobulin superfamily (red). Fine MECA- $79^{+}$vessels (green) are negative for ICAM-1, VCAM-1 and MAdCAM-1 (red). Note that most WLPTC carcinoma cells express ICAM-1 (red in top panels). Bar $=50 \mu \mathrm{m}$.

Fig 7. Expression of ICAM-1 (red) on DSPTC carcinoma cells. Note that a fraction of carcinoma cells also expresses MECA-79 glycoepitopes (green in left panel; yellow in right merged panel). $\quad$ Bar $=50 \mu \mathrm{m}$.

Fig 8. Various lymphocyte subsets attach to the luminal surface of HEV-like vessels induced in DSPTC. (A) Triple immunohistochemistry for MECA-79 (brown) and either CD3 (blue) and CD20/CD79a (red) (left panel), or CD4 (blue) and CD8 (red) (right panel). Note that in left panel, both $\mathrm{CD}^{+} \mathrm{T}$ cells (arrow) and CD20/CD79a ${ }^{+} \mathrm{B}$ cells (arrowhead) or in right panel CD4 ${ }^{+}$ helper $\mathrm{T}$ cells (arrow) and $\mathrm{CD}^{+}$cytotoxic $\mathrm{T}$ cells (arrowhead) attached to the luminal surface of MECA-79 $9^{+}$HEV-like vessels. $B a r=50 \mu \mathrm{m}$. (B) The number of respective $\mathrm{T}$ and $\mathrm{B}$ cells (left panel), or $\mathrm{CD}^{+}$helper $\mathrm{T}$ and $\mathrm{CD} 8^{+}$cytotoxic $\mathrm{T}$ cells (right panel) attached per HEV-like vessel. 
Data are presented as means $\pm \mathrm{SD} . \quad * * *, p<0.001$

Fig 9. Immunohistochemical profiles of DSPTC carcinoma cells (upper panels), non-neoplastic follicular epithelial cells in Hashimoto's thyroiditis (HT) (middle panels) and WLPTC carcinoma cells (lower panels). Serial tissue sections were subjected to immunohistochemistry for MECA-79, HECA-452 and S1. Signals were visualized with DAB (brown). All panels are counterstained with hematoxylin; left panels are stained with hematoxylin and eosin (HE). Bar $=50 \mu \mathrm{m}$.

Fig 10. E-selectin $\bullet \operatorname{IgM}$ chimera in situ binding assay. DSPTC carcinoma cells in tissue sections are decorated with E-selectin $\bullet \operatorname{IgM}$ chimeras (left panel) and binding was completely abolished in the presence of EDTA (that is, in the absence of divalent cations) (right panel). Signals are visualized with DAB (brown). Samples are counterstained with hematoxylin. Bar $=100 \mu \mathrm{m}$. 
Table 1 Clinicopathological features of DSPTC cases examined in this study

\begin{tabular}{ccccccc}
\hline Case \# & $\begin{array}{c}\text { Age } \\
\text { (years) }\end{array}$ & $\begin{array}{c}\text { Sex } \\
\text { (M or F) }\end{array}$ & $\begin{array}{c}\text { Lymphatic } \\
\text { invasion }\end{array}$ & $\begin{array}{c}\text { Vascular } \\
\text { invasion }\end{array}$ & $\begin{array}{c}\text { Lymph node } \\
\text { metastasis }\end{array}$ & $\begin{array}{c}\text { Distant } \\
\text { metastasis }\end{array}$ \\
\hline 1 & 25 & $\mathrm{~F}$ & + & - & + & Lung \\
2 & 19 & $\mathrm{~F}$ & + & - & + & - \\
3 & 31 & $\mathrm{~F}$ & + & - & + & - \\
4 & 53 & $\mathrm{~F}$ & + & - & + & - \\
5 & 44 & $\mathrm{~F}$ & + & - & + & - \\
6 & 25 & $\mathrm{~F}$ & + & - & + & - \\
7 & 35 & $\mathrm{~F}$ & + & - & + & - \\
8 & 32 & $\mathrm{~F}$ & + & - & + & - \\
9 & 28 & $\mathrm{~F}$ & + & - & + & Lung \\
10 & 29 & $\mathrm{~F}$ & + & - & + & - \\
11 & 49 & $\mathrm{M}$ & + & - & + & - \\
12 & 13 & $\mathrm{~F}$ & + & - & + & - \\
13 & 28 & $\mathrm{~F}$ & + & - & + & - \\
14 & 29 & $\mathrm{~F}$ & + & - & + & - \\
15 & 33 & $\mathrm{~F}$ & + & - & + & - \\
16 & 24 & $\mathrm{~F}$ & + & - & + & - \\
17 & 43 & $\mathrm{~F}$ & + & - & + & - \\
\hline
\end{tabular}


Figure 1
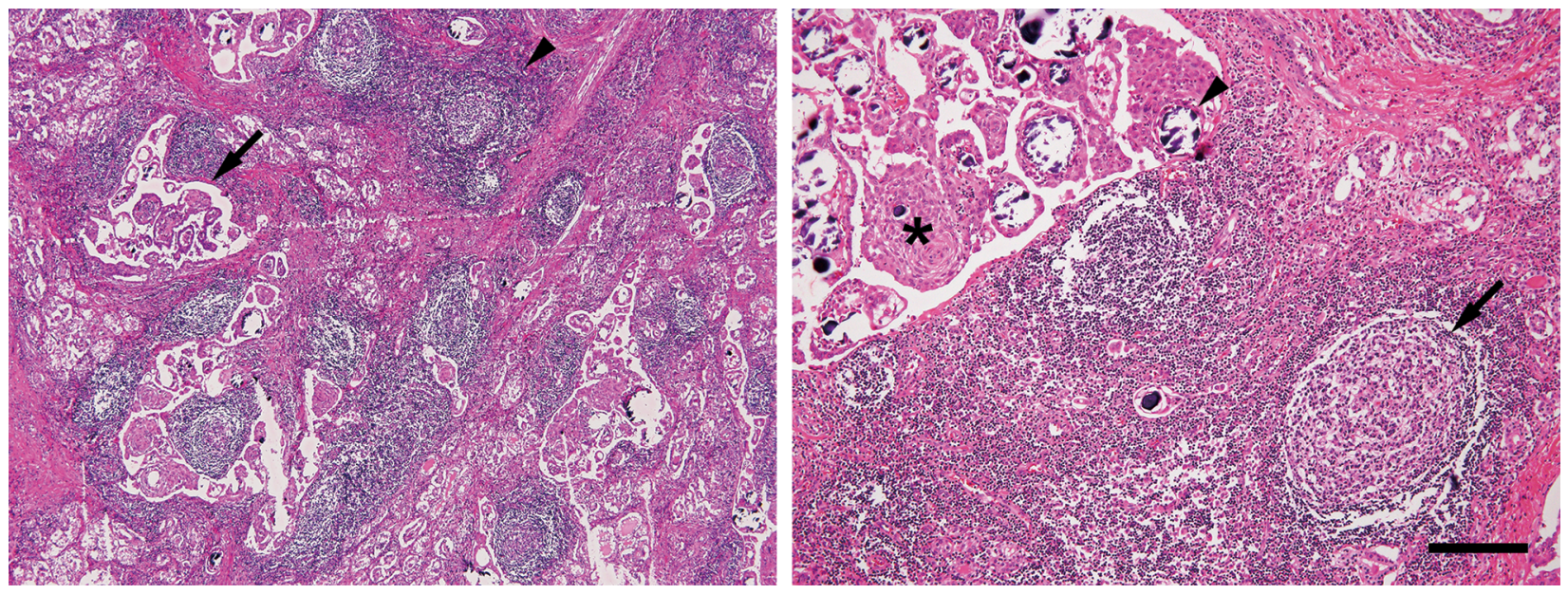
Figure 2

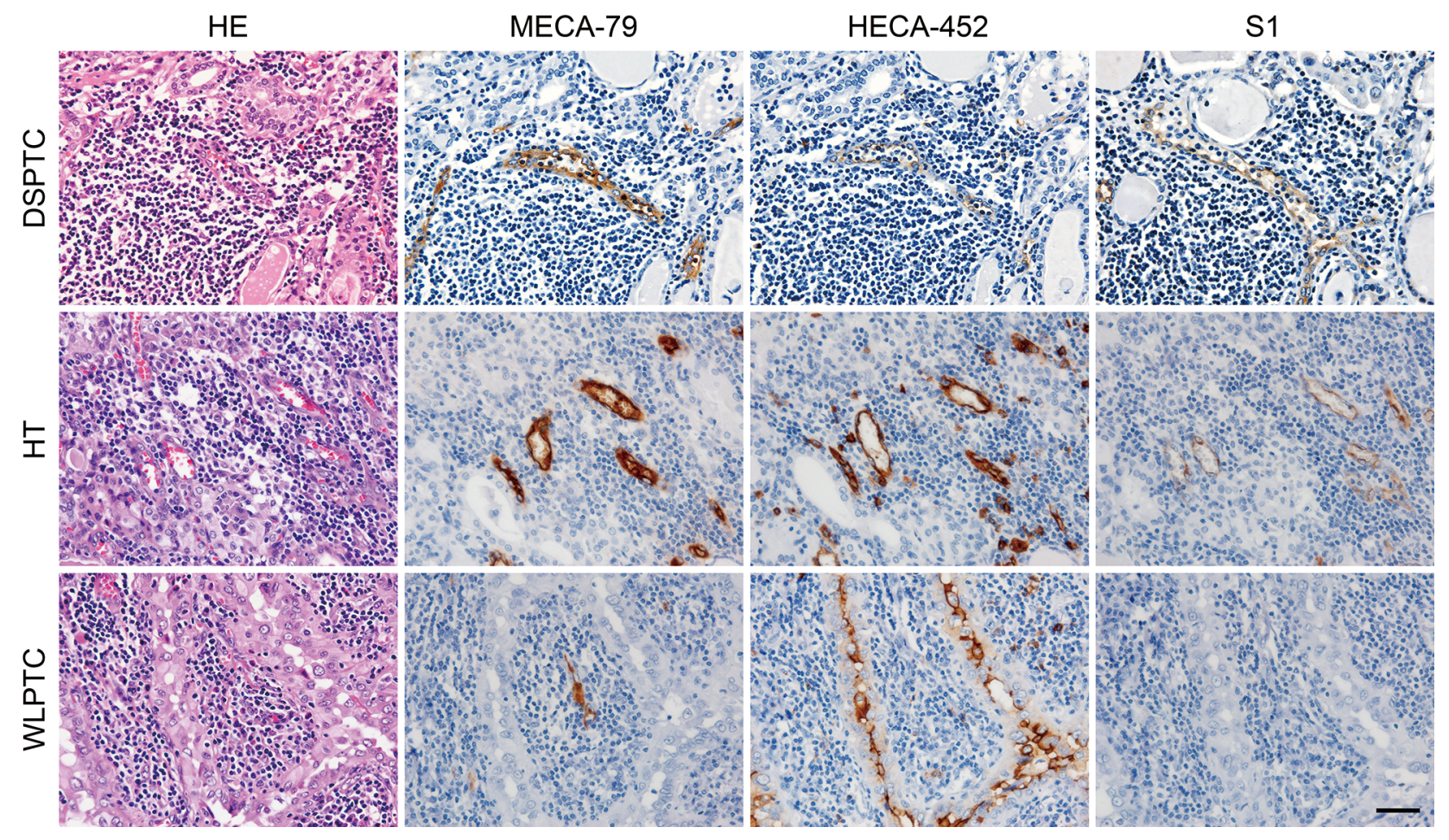


Figure 3

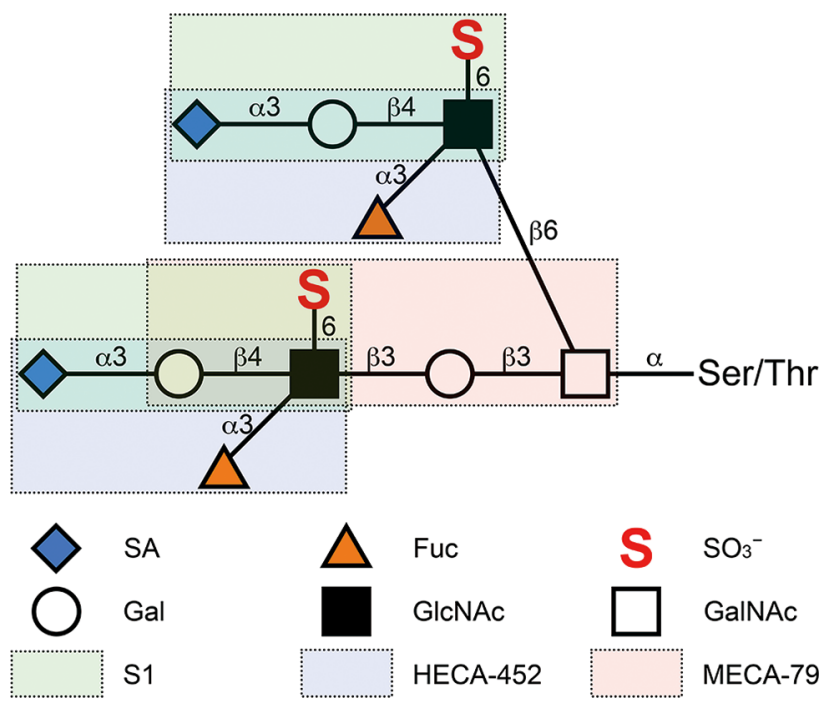


Figure 4

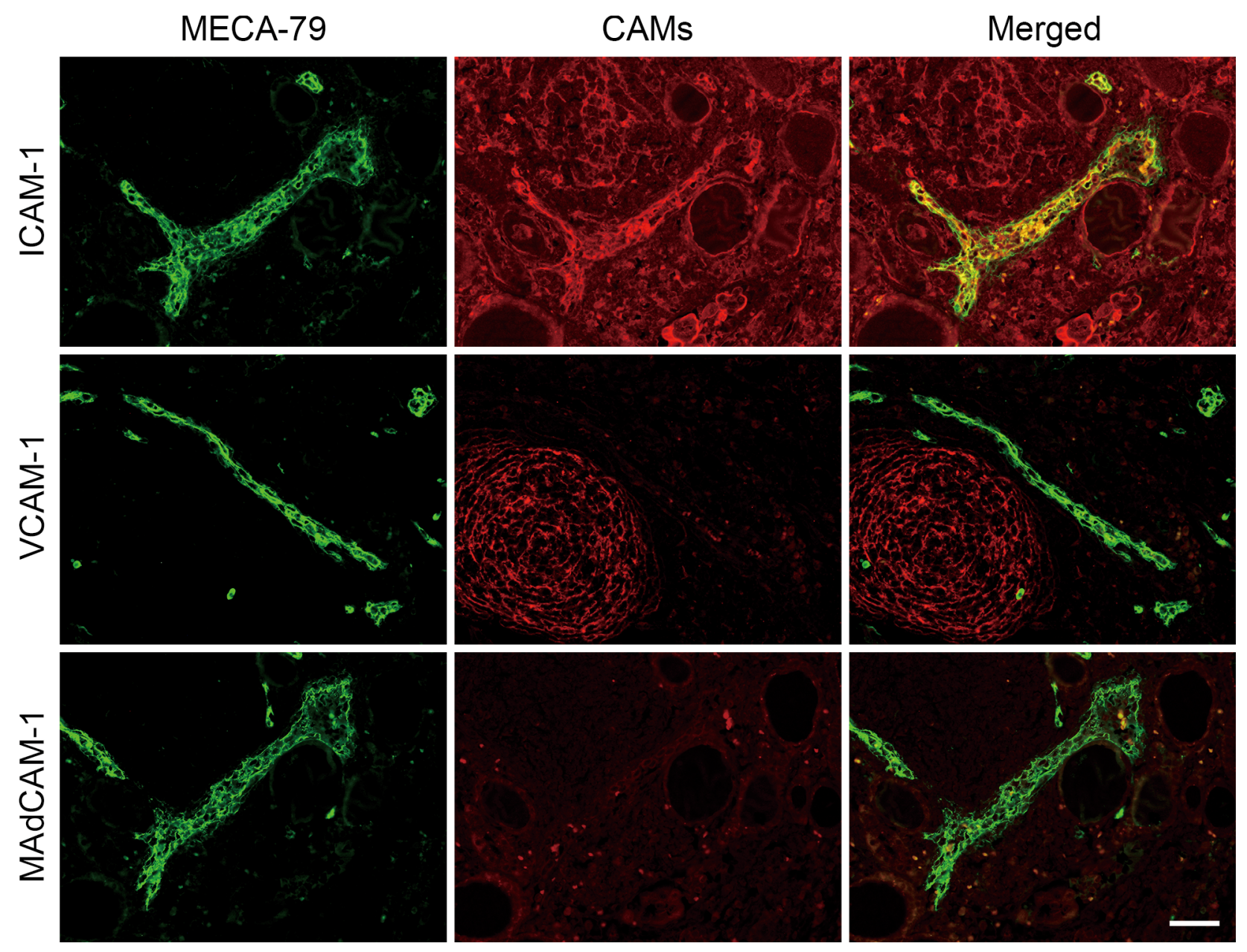


Figure 5

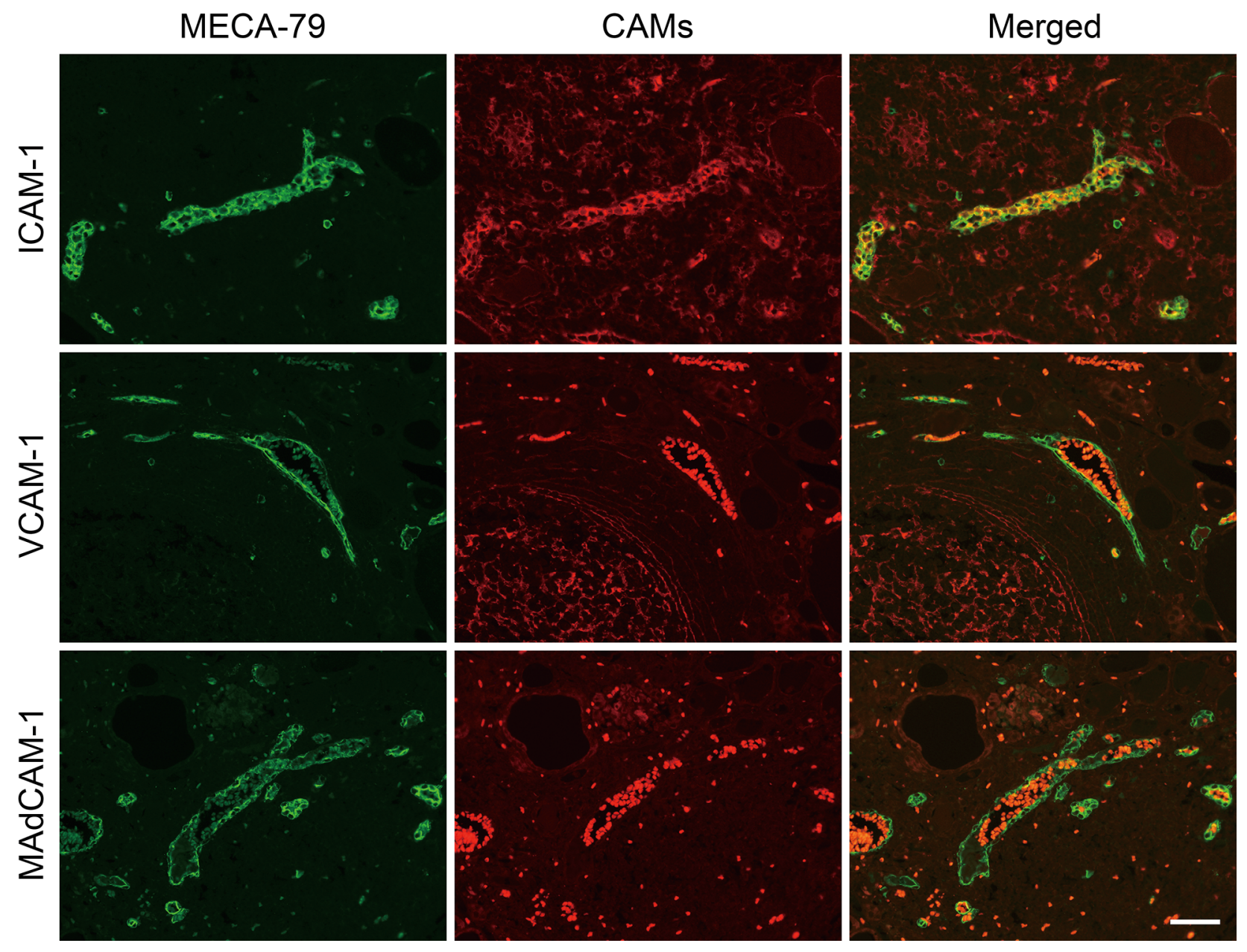


Figure 6

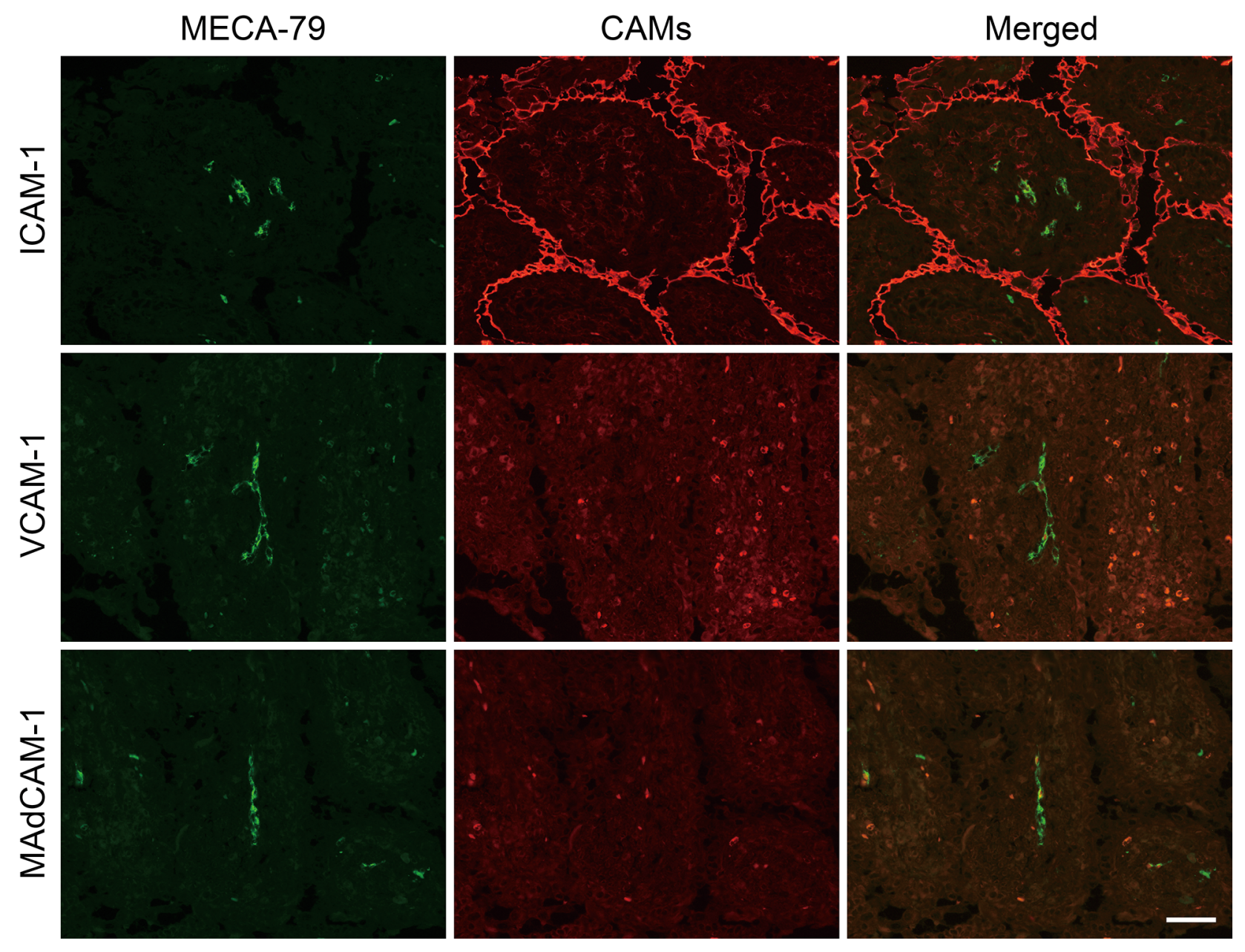


Figure 7

MECA-79

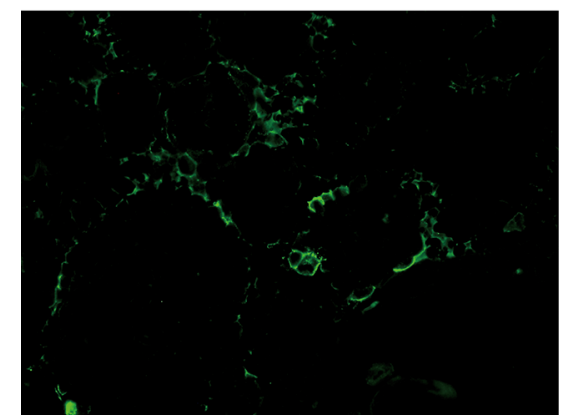

ICAM-1

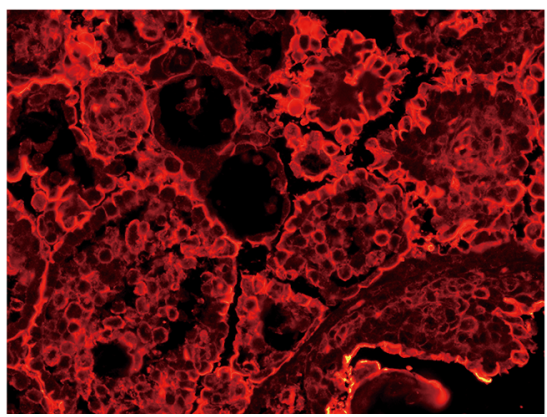

Merged

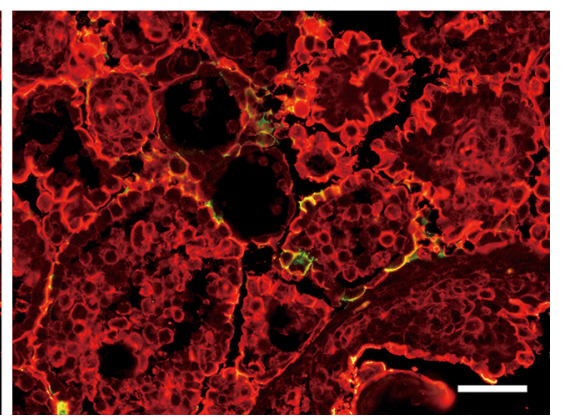


Figure 8

(A)

T, B, MECA-79

CD4, CD8, MECA-79
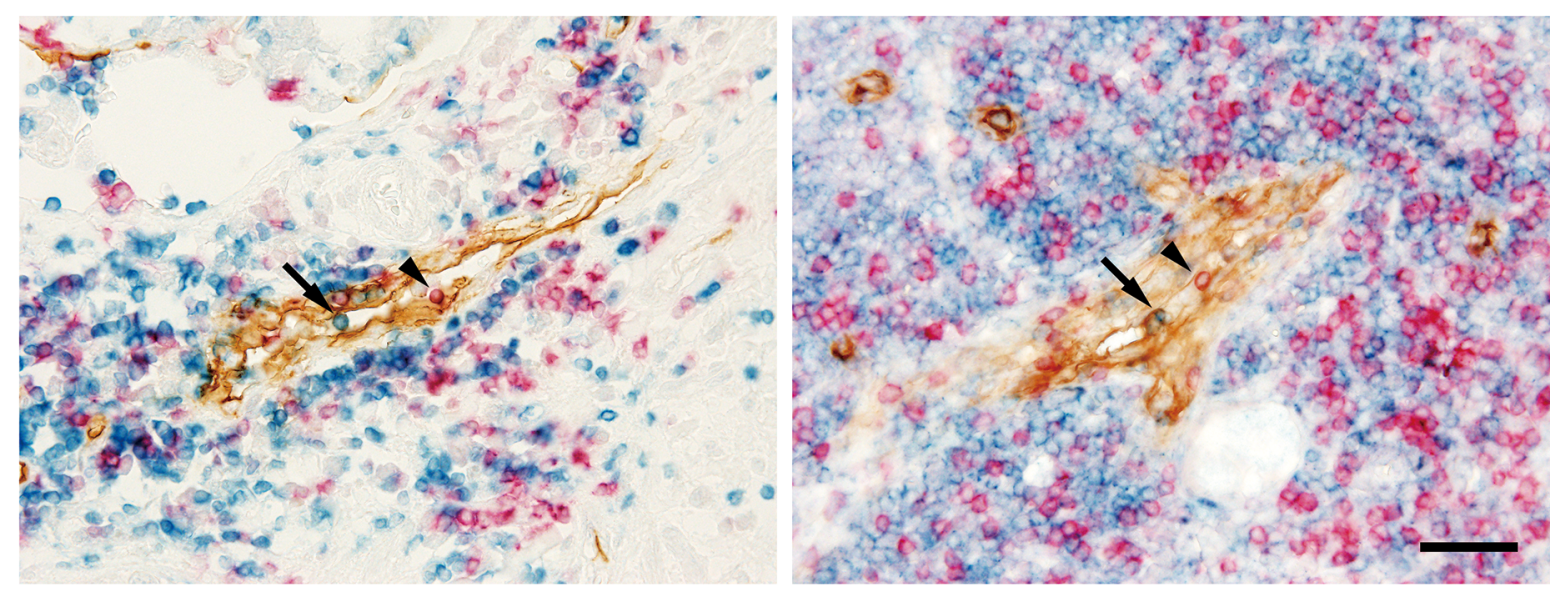

(B)
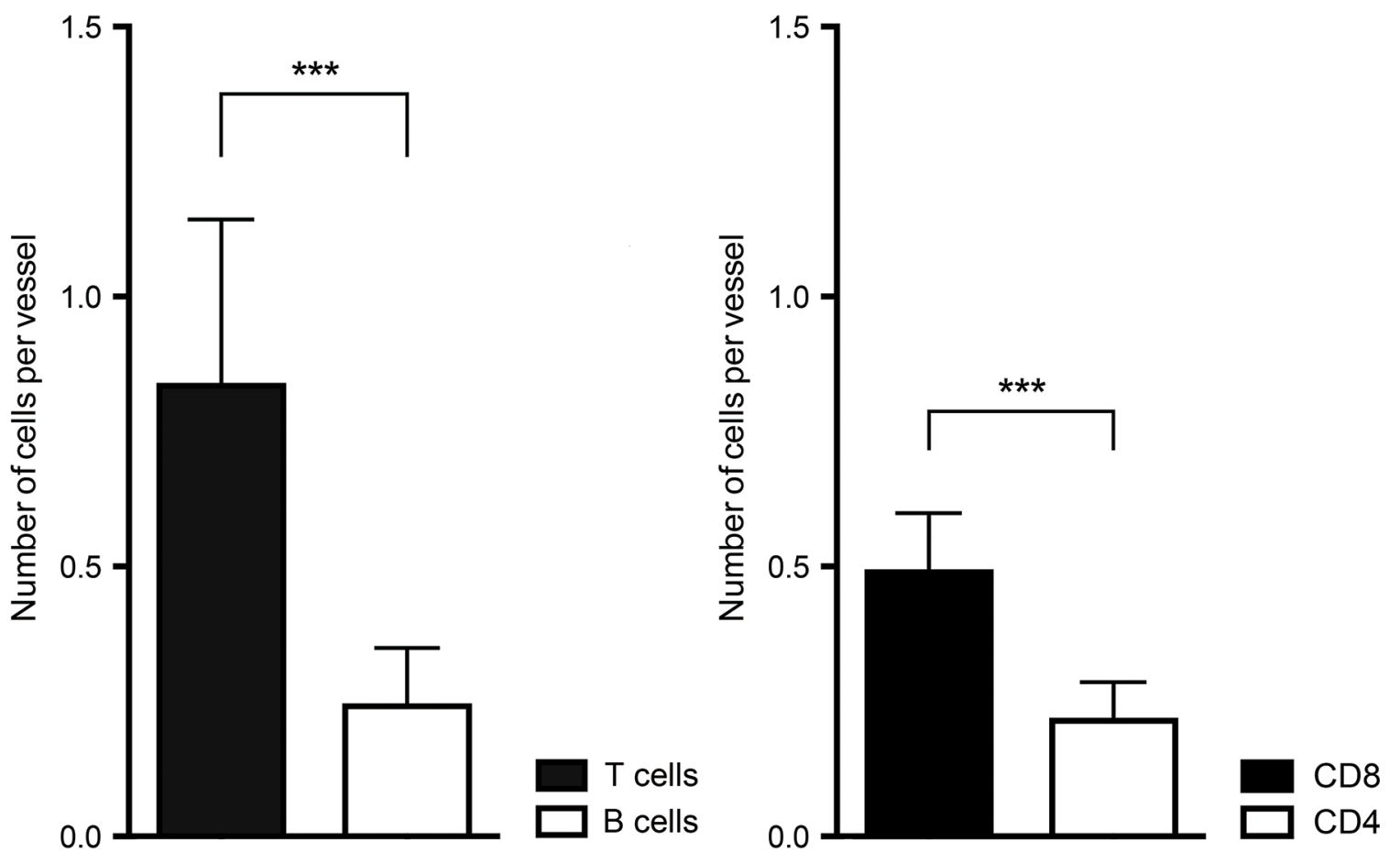
Figure 9

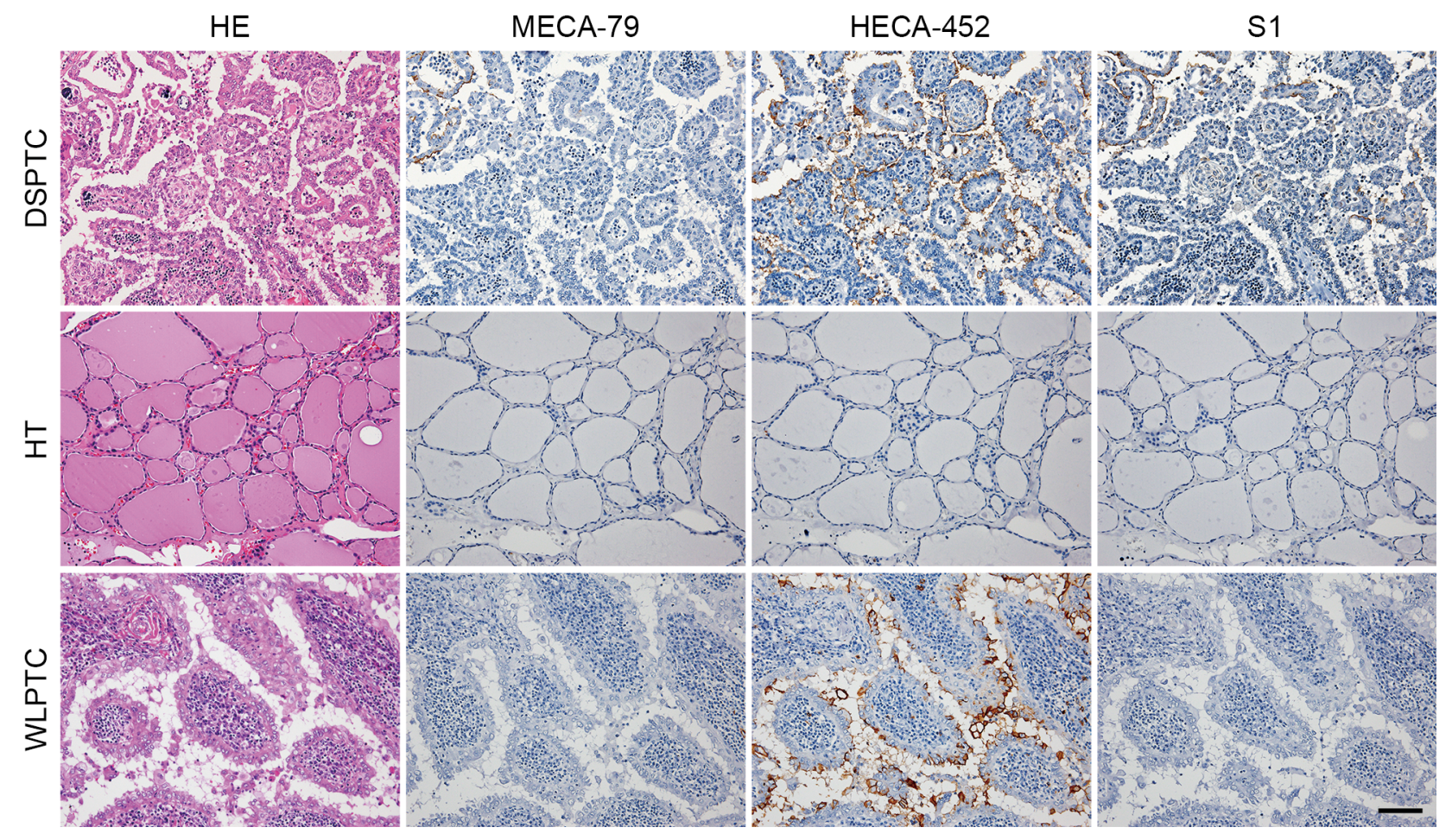


Figure 10

\section{without EDTA}

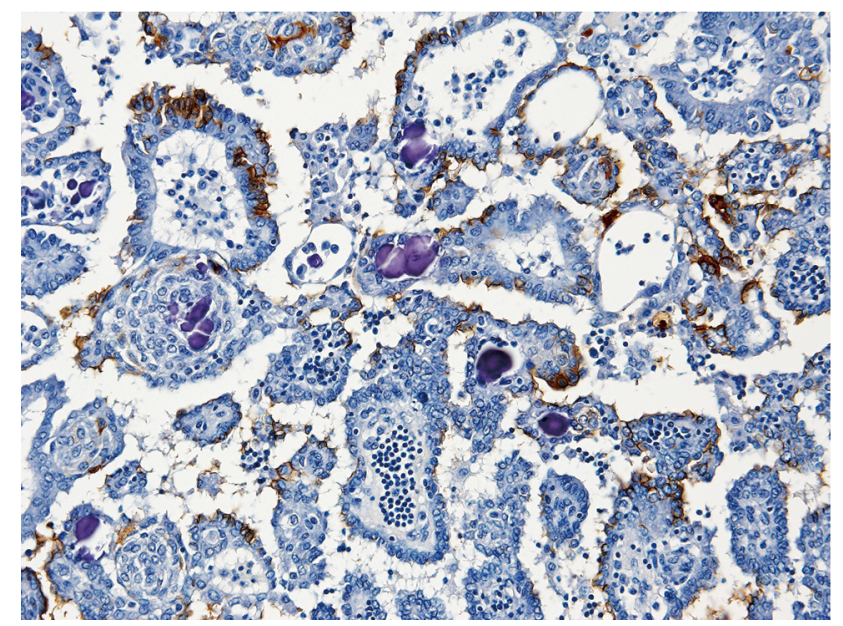

with EDTA

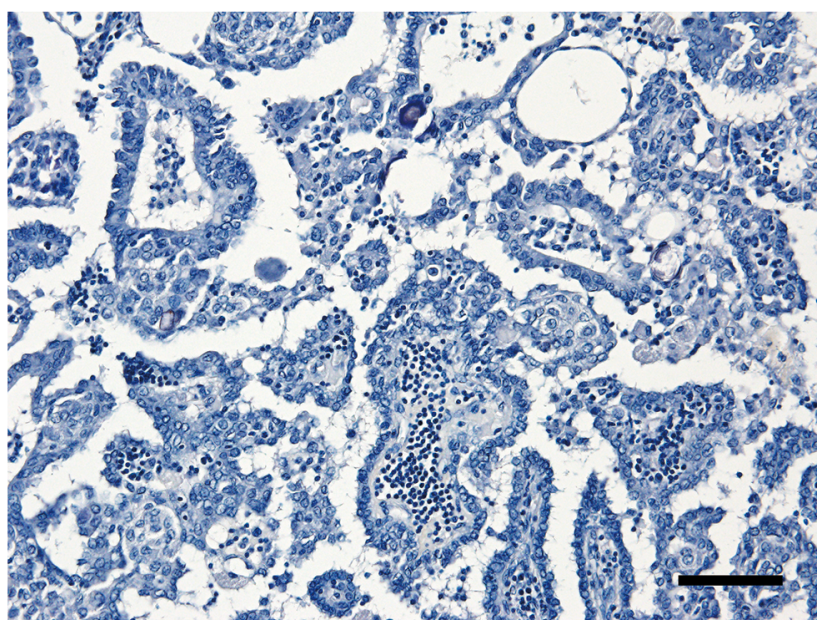

